\title{
THERMAL DEGRADATION OF RANDOM
}

\section{COPOLYESTERS BASED ON 1,4-BUTANEDIOL,}

\author{
TEREPTHALIC ACID AND DIFFERENT ALIPHATIC
}

DICARBOXYLIC ACIDS

Nina Heidarzadeh ${ }^{2}$, Mehdi Rafizadeh ${ }^{2 *}$, Faramarz A. Taromi, ${ }^{2}$ Luís J. del Valle, ${ }^{1}$ Lourdes Franco ${ }^{1}$, Jordi Puiggalí ${ }^{1 *}$

${ }^{1}$ Chemical Engineering Department, Escola d'Enginyeria de Barcelona Est-EEBE, c/Eduard Maristany 10-14, Barcelona E-08019, SPAIN

${ }^{2}$ Department of Polymer Engineering and Color Technology, Amirkabir University of Technology, PO Box 15875-441, Tehran, IRAN

Correspondence to: J. Puiggalí (E-mail: Jordi.Puiggali@upc.edu) and M. Rafizadeh (Email: $\underline{\text { mehdi@aut.ac.ir) }}$ 


\begin{abstract}
Thermal stability and degradation kinetics have been studied for a series of aliphaticaromatic copolyesters where the terephthalate content was varied between 30 mol-\% and 70 mol- $\%$. Succinate, adipate and sebacate were considered as the aliphatic dicarboxylate unit. All copolyesters were synthesized with a perfect random distribution by a thermal transesterification process from the corresponding homopolyesters.
\end{abstract}

A complex degradation was deduced for all copolymers taking into account the increment of the activation energy with conversion. In fact, thermogravimetric curves showed a minor decomposition process in the low conversion region that was more significant for the succinate derivative and specifically for that having the lowest aromatic content. The sebacate derivative was characterized by the presence of an additional and minor decomposition process that took place at the highest conversion. All copolyesters were defined by a major decomposition process, which has similar values of activation energy regardless of the method used to calculate them (e.g. Kissinger, KAS or Friedman methodologies). This decomposition reaction followed a $\mathrm{A}_{4}$ Avrami-Erofeev mechanism when Coats-Redfern and Criado methodologies were applied. In summary, all the studied copolymers thermally decompose following a complex process but in all cases the main degradation step corresponds to a similar degradation mechanism.

Keywords: Biodegradable polymers, aliphatic-aromatic copolyesters, terephthalic acid, succinic acid, sebacic acid, thermal degradation kinetics, isoconversional methods, thermal degradation mechanism. 


\section{INTRODUCTION}

Several biodegradable copolyesters are being considered as a good alternative to commodity polymers because they may have a similar performance while being environmentally friendly could contribute to reduce white pollution. Poly(alkylene dicarboxylate)s (PADs) probably constitute the most interesting family since their mechanical and thermal properties as well as their degradation rate could be easily tuned by employing different comonomer compositions [1]. In addition, some PADs could be obtained from monomers coming from renewable natural resources. For example, succinic acid can be produced by microbial synthesis [2] and becomes nowadays a suitable platform to synthesize other chemical compounds as it is the case of 1,4-butanediol [3,4]. Poly(butylene succinate) (PBS) is directly derived from these two monomers and currently is the most interesting PAD due to its exceptionally good thermal and mechanical properties together with its easy processability [5-8].

Nevertheless, another PADs are also being considered even though they display poorer properties. These limitations can be easily overcome by the incorporation of rigid aromatic dicarboxylic acid units in the main chain since they do not cause a sharp degradability reduction if they content is limited. Therefore, only certain ratios between aliphatic and aromatic dicarboxylic units have received an applied commercial interest. Ecoflex ${ }^{\mathrm{TM}}$ and Origo-Bi (previously Eastar Bio ${ }^{\mathrm{TM}}$ ) are two copolyesters produced by BASF and Novamont (previously Eastman), respectively. They are probably the most important ecological aliphatic-aromatic polyesters that have been commercialized so far [9]. These copolyesters are composed of soft aliphatic and hard aromatic segments, which are obtained by the reaction of 1,4butanediol with adipic acid and terephthalic acid, respectively [10]. Biodegradation 
of such aliphatic-aromatic copolyesters is well probed as well as their susceptibility to lipase-like hydrolases [11-15].

Limited and even contradictory studies have, up to now, been focused on the study of the thermal degradation kinetic mechanisms of aliphatic-aromatic polyesters. This point deserves a greater attention due to both, the increasing interest in their applications and the potential problems of their melt processing that could be derived from the relatively high melting temperatures. For example, it is well-known that some thermal degradation of poly (butylene terephthalate) (PBT) (i.e. the aromatic homopolymer) may occur at its processing temperature $\left(250-280^{\circ} \mathrm{C}\right)$. However, most degradation studies on PBT are mainly concerned to the characterization of decomposition products and the description of the involved reactions [16-18]. A complex multistage decomposition involving two major reaction pathways was firstly described on the basis of dynamic mass spectroscopy [16]. Thereafter it was found out that the formation of cyclic oligomers was predominant at temperatures below $290{ }^{\circ} \mathrm{C}$ whereas a $\beta$-hydrogen transfer was the characteristic mechanism at higher temperatures [17]. In all cases, scission products were so varied that the degradation routes are still not fully elucidated [18].

Regarding thermal degradation of aliphatic components, a notable study has been undertaken by Chrissafis et al. [19] on poly (butylene succinate) (PBS). In contrast with PBT, PBS showed a high thermal stability, with the onset degradation temperature being higher than $350{ }^{\circ} \mathrm{C}$ and obviously higher than its melting temperature $\left(115^{\circ} \mathrm{C}\right)$. A decomposition process involving two stages was again described. The first stage was very small and could only be slightly distinguishable in DTG thermograms. nth-order mechanisms were postulated as typical for degradation of polyesters [20]. Specifically $n$ 
$=0.75$ and 0.68 and activation energies of 128 and $189 \mathrm{~kJ} / \mathrm{mol}$ were determined for the first and second decomposition steps, respectively.

From TGA analysis of poly (alkylene adipate)s it was found that poly (ethylene adipate) PEAd and poly (propylene adipate) PPAd had lower thermal stability than poly (butylene adipate) (PBAd). Thermal degradation of PEAd was found to be satisfactorily described by one mechanism, with activation energy of $153 \mathrm{~kJ} / \mathrm{mol}$, while PPAd and PBAd followed two mechanisms having different activation energies. The first mechanism corresponded to a small mass loss with activation energies of 121 and 185 $\mathrm{kJ} / \mathrm{mol}$ for PPAd and PBAd, respectively, while the second one was attributed to the main decomposition mechanism, where substantial mass loss took place, with activation energies of 157 and $217 \mathrm{~kJ} / \mathrm{mol}$, respectively [21].

In recent years interesting attempts have also been focused to extend the range of application of PADs by using monomers such as sebacic acid or dodecanodioic acid that provide a large polymethylene sequence in the main polymer chain [22]. It is clear that polyesters having increased number of methylenes become progressively similar to polyethylene and consequently an improvement of properties is again expected. Nevertheless, thermal degradation studies of such compounds are scarce and merely report a high stability without performing additional kinetic analyses [23]. It is also surprising that scarce studies have been published on the degradation mechanism of poly(butylene aliphatic dicarboxylate-co-butylene terephthalate)s, being the studies mainly focused on the description of their thermal stability [24].

The present work tries to discern if the main decomposition process of poly(butylene aliphatic dicarboxylate-co-butylene terephthalate)s obeys a similar degradation mechanism and consequently a simplification/rationalization of previous reported data can be assumed. To this end a series of copolymers with an aromatic ratio varying from 
20 to $70 \mathrm{wt}-\%$ (respect to the total dicarboxylate content) will be considered. In addition, the possible influence of the methylene content of the aliphatic unit (i.e. from 2 to 8 methylene groups) will be evaluated for the representative intermediate composition of $50 \mathrm{wt}-\%$.

\section{EXPERIMENTAL SECTION}

\section{Materials}

Copolyester derived from 1,4-butanediol, terephthalic acid and dicarboxylic acids such as succinic, adipic and sebacic acids were synthesized by means of a thermal transesterification between the appropriate mixture of the aromatic (i.e. PBT) and aliphatic (i.e. PBS, PBAd or poly(butylene sebacate) (PBSe)) homopolymers (Fig. 1). This method easily allows preparing copolymers with different composition from the appropriate homopolymer mixture. For this purpose, the proper reaction conditions were selected to guarantee the occurrence of transesterification reactions and the achievement of a random microstructure.

Transesterification processes were performed in a reactor vessel a temperature of $250{ }^{\circ} \mathrm{C}$ while vacuum was applied (20 mbar). Titanium butoxide was employed as catalyst (1.4 mmol for $1 \mathrm{~mol}$ of dicarboxylic acid). Reaction was performed during approximately 150 min, being not detected any evidence of chain degradation (i.e. the mixer torque did not decrease during the transesterification process). A similar purification strategy was applied for all copolymers despite having clearly different solubility characteristics. Therefore, copolymers were dissolved in a strong solvent like 1,1,1,3,3,3,hexafluroisopropanol (HFIP) and precipitated in water; repeatedly washed with water, methanol and ether; and dried in a vacuum desiccator. Homopolymers were previously synthesized by a typical thermal polycondensation process from an excess of 1,4butanediol and the corresponding dicarboxylic acid [25]. 
Final copolymers are abbreviated as PBST-X, PBAdT-X and PBSeT-X for succinic, adipic and sebacic acid derivatives, respectively, being $\mathrm{X}$ the molar ratio of aliphatic dicarboxylic units with respect to the total content of dicarboxylic units.

\section{Measurements}

Molecular weights were estimated by size exclusion chromatography (GPC) via a liquid chromatograph (Shimadzu, model LC-8A) equipped with an Empower computer program (Waters). A PL HFIP gel column (Polymer Lab) and a refractive index detector (Shimadzu RID-10A) were employed. The polymer was dissolved and eluted in HFIP containing $\mathrm{CF}_{3} \mathrm{COONa}(0.05 \mathrm{M})$ at a flow rate of $1 \mathrm{~mL} / \mathrm{min}$ (injected volume $100 \mu \mathrm{L}$, sample concentration $2.0 \mathrm{mg} / \mathrm{mL}$ ). The number and weight average molecular weights were calculated using polymethyl methacrylate (PMMA) standards.

${ }^{1} \mathrm{H}-\mathrm{NMR}$ spectra were acquired with a Bruker AMX-300 spectrometer operating at 300.1 MHz. Chemical shifts were calibrated using tetramethylsilane as an internal standard. A mixture $(1: 1 v / v)$ of deuterated chloroform and trifluoroacetic acid was used Thermal degradation was performed with approximately $5 \mathrm{mg}$ samples in a Q50 thermogravimetric analyzer of TA Instruments under a flow of dry nitrogen $(40 \mathrm{~mL} / \mathrm{min}$ and $60 \mathrm{~mL} / \mathrm{min}$ to the balance and sample areas, respectively) at heating rates of 3, 5, 10 and $20{ }^{\circ} \mathrm{C} / \mathrm{min}$ within the temperature range of 30 to $600{ }^{\circ} \mathrm{C}$. PeakFit v4.12 program by Jandel Scientific Software with an asymmetric function known as "asymmetric double sigmoidal" was employed to deconvolute the derivative thermogravimetric analysis (DTG) curves.

\section{Evaluation of the activation energy for thermal degradation processes}

According to non-isothermal kinetic theory, thermal degradation of a polymer can be explained by the following equation: 


$$
\frac{d \alpha}{d T}=\frac{1}{\beta} A \exp \left(\frac{-E}{R T}\right) f(\alpha)
$$

where $\alpha$ is the degree of conversion, $T$ is the absolute temperature, $\beta$ is the heating rate, $R$ is the gas constant, $f(\alpha)$ is the differential conversion function and $A$ and $E$ are the pre-exponential factor and the activation energy for the decomposition reaction, respectively.

Activation energies can be determined by Kissinger [26] and and more accurately by advanced isoconversional methods such as Kissinger-Akahira-Sunose (KAS) $[26,27]$ and Friedman [28,29], which do not require the knowledge of the exact thermodegradation mechanism. Integral (KAS) and differential (Friedman) methods are based on the isoconversional principle, which states that the reaction rate is only a function of the temperature at a constant extent of conversion.

Isoconversional methods have the advantage that activation energy value can be determined during the whole heating process. Specifically, the KAS method is based on the integration of Eq. (1), which after reordering, becomes:

$$
\ln \frac{\beta}{T^{2}}=\ln \left[\frac{A R}{g(\alpha) E}\right]-\frac{E}{R T}
$$

where $g(\alpha)$ is the integral conversion function given by Eq. (3):

$$
g(\alpha)=\int_{0}^{\alpha} \frac{d \alpha}{f(\alpha)}=(A / \beta) \int_{0}^{T} e^{-\frac{E}{R T}} d T
$$

For each degree of conversion and each step of the degradation process the activation energy can be obtained from the slope of the linear representation of $\ln \left(\beta / T^{2}\right)$ versus $1 / T$.

The Friedman method derives from the logarithmic form of the rate (Eq. (1)) and is used to obtain the values of activation energies over a wide range of conversions. By 
plotting $\ln (\beta d \alpha / d T)$ versus $1 / T$ from thermogravimetric curves recorded at several heating rates, the activation energy can be calculated as follows:

$$
\ln \left[\frac{\beta d \alpha}{d T}\right]=\ln A+\ln f(\alpha)-\frac{E}{R T}
$$

The Kissinger method [30] also allows the determination of the activation energy considering only the maximum of the DTG curve for each degradation step. The method is based on the following equation:

$$
\ln \left(\beta / T_{\max }^{2}\right)=\ln (A R / E)+\ln \left[n\left(1-\alpha_{\max }\right)^{n-1}\right]-E / R T_{\max }
$$

where $\beta$ is the heating rate, $T_{\max }$ is the temperature at the maximum reaction rate, $\alpha_{\max }$ is the conversion at this $T_{\max }, n$ is the reaction order and $A$ is the frequency factor. The activation energy of the degradation step could be assessed by the slope of the linear regression from the plot $\ln \left(\beta / T_{\max }{ }^{2}\right)$ versus $1 / T_{\max }$.

It should be pointed out that Kissinger is not an isoconversional method since the peak temperature is obtained at different heating rates, in addition the extent of conversion associated with the peak is known to change with the heating rate [31,32]. Moreover, the calculated activation energy value might lose its meaning if it varies throughout the degradation process.

\section{Determination of thermal degradation mechanisms}

The Coats-Redfern method [33] calculates the activation energy using conventional $g(\alpha)$ functions [34,35] according to Eq. (6), which was derived by considering an asymptotic approximation $(2 R T / E \ll 1)$ :

$$
\ln \frac{g(\alpha)}{T^{2}}=\ln \left(\frac{A R}{\beta E}\right)-\frac{E}{R T}
$$

Care should be taken as this equation was obtained assuming that the activation energy was independent of the degree of conversion. 
The slope of the linear plot of $\ln g(\alpha) / T^{2}$ versus $1 / T$ allowed the determination of the activation energy for each possible model and the selection of the possible model considering the agreement with the previously calculated activation energy and the achievement of a good regression coefficient. With the Coats-Redfern method, it is also possible to determine the frequency factor $(A)$ from the intercept at the origin, and therefore the complete kinetic triplet $(E, A$ and $f(\alpha)$ ), which defines the variation of the degree of conversion with temperature (Eq. (1)).

The master curve procedure [36] is an alternative method to specify the most suitable kinetic model for a degradation process. A differential master equation can be easily derived from Eq. (1) using the conversion $\alpha=0.5$ as a reference and assuming constant values for the activation energy and the pre-exponential factor:

$$
\frac{f(\alpha)}{f(0.5)}=\frac{d \alpha / d t}{(d \alpha / d t)_{0.5}} \frac{\exp \left(-E / R T_{0.5}\right)}{\exp (-E / R T)}
$$

where $(d \alpha / d t)_{0.5}, T_{0.5}$ and $f(0.5)$ are the reaction rate, temperature and differential conversion function at $\alpha=0.5$, respectively.

The left hand side of the Eq. (7) is a reduced theoretical curve which is characteristic of each kinetic model. The activation energy of the right hand side is chosen as the most representative of the overall process. By comparing both sides of the equation, it is possible to discern the kinetic model that best describes the experimental reaction process.

\section{RESULTS AND DISCUSSION}

\section{Synthesis and characterization of aliphatic-aromatic copolyesters}

All copolymers were obtained with a practically quantitative yield from the corresponding homopolymers ( $\geq 90 \%$ after purification). For the succinic acid series, it was found that the average molecular weights increased (Table 1) with the terephthalic 
content since the starting molecular weight of PBT was slightly higher than that. determined for PBS (i.e. 18,000 g/mol with respect to 12,000 g/mol). Polydispersity ranged between 2.62 and 2.12, a value typical of samples obtained from thermal polyconsensation reactions (i.e. the synthesis procedure for the homopolymer precursors).

FTIR spectra of copolymers (Figure S1) represented the characteristic absorption bands for methylene (ca. 2930 and $2850 \mathrm{~cm}^{-1}$ ), $\mathrm{C}=\mathrm{O}\left(\mathrm{ca} .1700 \mathrm{~cm}^{-1}\right.$ ), aromatic $\mathrm{C}-\mathrm{O}$ (ca. 1285 and $1180 \mathrm{~cm}^{-1}$ ) and aliphatic C-O (ca. 1220 and $1080 \mathrm{~cm}^{-1}$ ) groups. The relative intensity of methylene and aromatic $\mathrm{C}-\mathrm{O}$ groups increased with the length of the aliphatic comonomer and the aromatic content, respectively.

${ }^{1} \mathrm{H}$ NMR spectra allowed verifying the copolymer composition through the integration from the characteristic peaks of aromatic $(8.11 \mathrm{ppm})$ and aliphatic $\left(\mathrm{COCH}_{2}\right.$ protons at 2.34-2.76 ppm) units (Fig. 2), which allowed determining the corresponding ( $f_{T}$ and $\left.f_{A}\right)$ mole fractions. Results were in full agreement with the homopolymer feed ratio (Table 1). Furthermore, no additional signals to those expected from the chemical structure as for example those associated with terminal groups or even signals indicative of the occurrence of secondary reactions were detected in the spectra. Therefore, transesterification reaction was not affected by any evidence of thermal degradation or crosslinking reactions. Copolymer molecular weights should be higher than the estimated value from GPC measurements, probably as a result of the inaccuracy derived from the use of PMMA standards and the greater chain stiffness when copolymers have a high terephthalic acid content.

NMR analysis was also useful to demonstrate that the selected reaction conditions (i.e. catalysts, temperature and time) were appropriated to obtain a random microstructure. A typical analysis was carried out taking into account the sequence sensitivity of $\mathrm{OCH}_{2}$ 
protons that appear in the 4.50-4.00 ppm region. Fig. 2 shows the assignment of the four observed triplets. Similar profile intensities were obtained from a determined composition independently of the length of the aliphatic dicarboxylic unit.

The respective areas of the observed triplets were used to determine the fractions corresponding to TBT $\left(f_{T T}\right)$, TBA $\left(f_{T A}\right)$, ABT $\left(f_{A T}\right)$, and $\mathrm{ABA}\left(f_{A A}\right)$ sequences. Obviously $f_{T A}$ and $f_{A T}$ should be equal, being taken its averaged value for the following calculations. It was therefore possible determining the probability of finding a $\mathrm{T}$ unit next to an $\mathrm{AB}$ sequence $\left(P_{A T}\right)$ as well as the probability of finding an aliphatic unit next to a TB sequence $\left(P_{T A}\right)$ :

$$
\begin{aligned}
& P_{A T}=f_{A T} / f_{A} \\
& P_{T A}=f_{T A} / f_{T}
\end{aligned}
$$

Block length of $\mathrm{AB}$ and $\mathrm{TB}$ sequences could also be calculated as:

$$
\begin{aligned}
& L_{n A B}=1 / P_{A T} \\
& L_{n T B}=1 / P_{T A}
\end{aligned}
$$

The degree of randomness $(r)$ is defined as the summation of the two probabilities $\left(P_{\mathrm{AT}}\right.$ and $\left.P_{\mathrm{TA}}\right)$, in which the values 2,1 and lower than 1 are indicative of alternating, random, and blocky distributions. The limit value of 0 logically indicates a mixture of the two homopolymers. Analysis of microstructure through the evaluation of the randomness parameter is highly usual as applied for example in the study of copolymers attained from copolymerization of different lactones [37,38].

Values summarized in Table 1 indicate that all the studied samples had a composition close to the theoretical one, although copolymers were slightly impoverished on the aromatic units probably as a consequence of the lower molecular weight and the higher content in butanediol units of terephthalate prepolymers which caused a distortion in the calculation of theoretical feed ratio for the transesterification step. Results also 
demonstrated that the three samples were associated with degree of randomness values close to 1.0, indicating a perfect statistical distribution. Namely, transesterification reactions between prepolymers of each dicarboxylic acid should take place at high reaction temperature, hindering the possibility to achieve a blocky structure.

\section{Thermal degradation of aliphatic-aromatic copolyesters}

All the studied copolyesters showed a significant decomposition in a nitrogen atmosphere at temperatures between 290 and $460{ }^{\circ} \mathrm{C}$ except for the sebacic acid derivative, which degradation finished at around $500{ }^{\circ} \mathrm{C}$ at the highest heating rate (i.e. $20{ }^{\circ} \mathrm{C} / \mathrm{min}$ ). Logically, thermogravimetric traces shifted to higher temperatures as the heating rate increased (Table 2, Figures S2 and S3), being possible to determine the activation energy associated with the decomposition process from this dependence as will then be discussed.

The summarized degradation data indicated that the onset degradation temperature was always relatively low (e.g. close to $250{ }^{\circ} \mathrm{C}$ for a heating rate of $3{ }^{\circ} \mathrm{C} / \mathrm{min}$ ) and was in agreement with the reported data for PBT. Therefore the incorporation of terephthalic units decreased the thermal stability of the corresponding aliphatic polyester considering that reported onset temperatures for them were close to $330{ }^{\circ} \mathrm{C}$ [19]. This effect was still observed for a low aromatic content such as 30 mol-\%.

Degradation data showed also that the main degradation process was practically not influenced with the increase of the aliphatic content. This feature can be easily deduced considering the temperatures at which decomposition reaches $50 \%\left(T_{0.5}\right)$. Thus, temperatures of 371,369 and $366^{\circ} \mathrm{C}$ at a heating rate of $3{ }^{\circ} \mathrm{C} / \mathrm{min}$ were observed for PBST-30, PBST-50 and PBST-70 samples, respectively. Note that the three polymers of this series should have succinic terminal groups and consequently a similar degradation mechanism should be expected for the minority first degradation step. In the same way, 
moderate changes of $T_{0.5}$ were observed when the length of the aliphatic comonomer changed (i.e. temperatures of 369,375 and $380{ }^{\circ} \mathrm{C}$ were determined for PBST-50, PBAdT-50 and PBSeT-50, respectively). Note that the small variations observed in this case should be a consequence of the lower temperature associated to the first degradation step for polymers having succinic terminal groups and the higher temperature associated to the also minoritary secondary degradation process that occur at the end of the degradation process for the sebacate derivative as below explained.

In all cases, the degree of degradation or conversion, $\alpha$, at a given temperature was calculated from the thermogravimetric traces as:

$$
\alpha=\left(\mathrm{W}_{0}-\mathrm{W}\right) /\left(\mathrm{W}_{0}-\mathrm{W}_{\infty}\right)
$$

where $W_{0}, W$ and $W_{\infty}$ are the initial weight, the weight at the selected temperature and the final weight at the end of the degradation process, respectively.

Fig. 3 plots the degree of conversion versus temperature curves for the three copolymers containing succinic acid units at all tested heating rates, together with the corresponding DTG derivative curves. Graphs corresponding to the adipic and sebacic acid derivatives are provided in Fig. 4.

DTG curves of succinic acid derivatives were highly asymmetric (see dashed ellipsoids in Fig. 3) including a small shoulder at lower temperature ranges. This low temperature degradation process was clearly observable for the copolymer with the lowest terephthalic acid content (i.e. PBST-70) at lower heating rates (see red arrow in Fig. 3c). In addition, a small shoulder could also be detected (see blue arrows in Fig. 3) before the main decomposition peak. In fact, degradation curves were performed in triplicate for all samples at the low temperature heating rate in order to verify the existence of the indicated small second shoulder as shown in Figure S4. Therefore, all PBST samples had a complex degradation process. The asymmetry in the lowest temperature region 
diminished for the adipic and sebacic acid derivatives, but a complex process could still be clearly inferred for the PBSeT-70 sample. It should be noted that in this case a clear peak at a temperature higher than that of the corresponding main decomposition process could be observed (see red arrows in Fig. 4b).

\section{Activation energy for the decomposition of succinate-co-terephthalate copolyesters}

The activation energy from the experimental degradation profiles showed a steady increase as calculated from the KAS or Friedman methods (e.g. Fig. 5), and as expected for a complex decomposition process where the last step had the higher activation energy. Specifically, the activation energy varied from $110 \mathrm{~kJ} / \mathrm{mol}$ to $158 \mathrm{~kJ} / \mathrm{mol}$ and from $148 \mathrm{~kJ} / \mathrm{mol}$ to $165 \mathrm{~kJ} / \mathrm{mol}$ for KAS and Friedman, respectively. The lower value of the activation energy, which is associated with the initial decomposition processes, justified that these steps were enhanced by decreasing the heating rate. A feature that is observed in the DTG curves, since in this case degradation occurred at lower temperatures.

Degradation kinetics of the different copolyesters could be studied by analyzing the different decomposition processes separately. A first approach involved the treatment of the single curves obtained after mathematical deconvolution of the experimental DTG traces. Fig. 6a shows specifically the profile of the PBST-70 sample obtained at 3 ${ }^{\circ} \mathrm{C} / \mathrm{min}$ where three peaks could be distinguished after deconvolution. Fig. $6 \mathrm{~b}$ shows rather constant KAS and Friedman activation energies that varied in the $143-158{ }^{\circ} \mathrm{C}$ $\mathrm{kJ} / \mathrm{mol}$ and $154-167 \mathrm{~kJ} / \mathrm{mol}$ ranges, respectively, when the mean deconvoluted peak was analyzed. The mean values $(151 \mathrm{~kJ} / \mathrm{mol}$ and $161 \mathrm{~kJ} / \mathrm{mol})$ were lower but very close to the maximum activation energies determined from the non deconvoluted profiles (i.e. $158 \mathrm{~kJ} / \mathrm{mol}$ and $165 \mathrm{~kJ} / \mathrm{mol})$. 
Rather constant activation energies (i.e. 156 and 159 kJ/mol for PBST-30 and PBST-50, respectively) were attained for the other two succinic acid derivatives when the Friedman method was applied (Fig. 7). Nevertheless, greater fluctuations in energy were observed when the KAS methodology was applied. In this case, only conversions equal or higher than 0.4 should be considered in order to get a practically constant energy. The average values were slightly underestimated (i.e. $143 \mathrm{~kJ} / \mathrm{mol}$ and $147 \mathrm{~kJ} / \mathrm{mol}$ for PBST-30 and PBST-50, respectively), as typically found when comparing the results from the Friedman and KAS methods. In fact, the former solves the differential kinetic form (Eq. 1) without approximations whereas the latter uses a close-form approximation [39] to derive the integral function (Eq. 2), thus providing a less accurate activation energy value. Nevertheless, calculations based on KAS are considered necessary since degradation mechanisms are then studied considering the typical Coats-Redfern approach, which is based on an integral equation as it is the case of the KAS methodology.

Results indicated that the activation energy of the main decomposition step was practically independent of the ratio between aliphatic and aromatic dicarboxylic units. Note that a practically constant value was observed when the more accurate Friedman data were considered (i.e. from $156 \mathrm{~kJ} / \mathrm{mol}$ to $161 \mathrm{~kJ} / \mathrm{mol}$ ). Logically, a similar degradation mechanism could be expected for the main decomposition step of the studied copolyesters.

The activation energies of the main degradation step were also comparable for the three succinic acid derivatives when the Kissinger method was applied which, despite being an approximate non isoconversional method, has the advantage of using only welldefined peak temperatures. Thus, results are not dependent on mathematical deconvolution accuracy if degradation is associated to a clearly dominant peak. Fig. 8 
showed that the slopes corresponding to the three copolymers were highly similar although a slightly higher value was observed for PBST-70. Specifically, the calculated activation energies of 147,140 and $155 \mathrm{~kJ} / \mathrm{mol}$ from $\mathrm{X}=30 \%$ to $70 \%$ did not show a specific trend with the increase of the aliphatic content. The average value corresponded to $147 \mathrm{~kJ} / \mathrm{mol}$ and was in relatively good agreement with the average energy deduced from the isoconversional KAS method (i.e. $145 \mathrm{~kJ} / \mathrm{mol}$ ).

\section{Degradation kinetic mechanism of succinate-co-terephthalate copolyesters}

The Coats-Redfern method was applied to determine the degradation mechanism associated with the main decomposition step of PBST copolymers. Nowadays, different methodologies have been proposed as more accurate (e.g. Madhysudanan [40], Tang [41] and Wanjun [42] methodologies). Nevertheless, discrimination between the different possible models could be effectively performed in our case since selection was finally based on the closeness between the derived activation energies and those experimentally determined, which in all cases pointed out to only one possible mechanism.

Later, a number of authors [35-36] suggested different solutions for the temperature integral in Equation (8), insisting that they increase the accuracy with which the kinetic parameters are calculated. For instance, Madhysudanan - Krishnan - Ninan [35] suggested the Equation (16):

Specifically, Table 3 summarizes the activation energies determined for PBST-70 as a representative copolymer and considering different heating rates. Good correlation coefficients were generally found for all models. However, it is clear that only the $\mathrm{A}_{4}$ Avrami-Erofeev model $\left(f(\alpha)=4(1-\alpha)[-\ln (1-\alpha)]^{1 / 4}\right.$ and $\left.g(\alpha)=[-\ln (1-\alpha)]^{1 / 4}\right)$ gave an activation energy that varied within a range (i.e. 141-163 $\mathrm{kJ} / \mathrm{mol}$ ) which was in agreement with the values computed by the KAS $(151 \mathrm{~kJ} / \mathrm{mol})$ and Friedman $(161$ $\mathrm{kJ} / \mathrm{mol}$ ) methods. The average value was $158 \mathrm{~kJ} / \mathrm{mol}$, namely between the low and the 
high energies deduced from the two isoconversional methods. The second best agreement corresponded to the $A_{3}$ model, but both the range of energy and the average value $(152-223 \mathrm{~kJ} / \mathrm{mol}$ and $192 \mathrm{~kJ} / \mathrm{mol}$, respectively) were clearly higher than the experimental values. After the kinetic model was selected, it was possible to calculate the frequency factor $\left(\ln \left(A / \mathrm{min}^{-1}\right)=27\right)$, and therefore determine the complete kinetic triplet ( $E, A$ and $f(\alpha)$ ) for the considered degradation step (Table 4). Results were similar for PBST-30 and PBST-50, being the corresponding data summarized in Table 4. Results are highly interesting since demonstrated that the main degradation step of copoly(butylene dicarboxylate)s follows the same kinetic mechanism independently of their succinate/terephthalate ratio. In this way, a simple interpretation of thermal degradation for the given series is derived, contrasting with the puzzling data/information that up to now has been provided.

The $\mathrm{A}_{4}$ model was also confirmed for the PBST-70 copolymer by comparing the $f(\alpha)$ function normalized at $\alpha=0.5$ for all the kinetic models with the right hand side of equation 7 as calculated for selected conversions and assuming the average activation energies determined for the copolymer (Fig. 9). The model points out a propagation of thermal degradation through nuclei formation processes.

\section{Activation energy for the main decomposition process of adipate/sebacate-co- terephthalate copolyesters}

Analyses of DTG curves were slightly different for the adipic and the sebacic acid detivatives since the latter showed a small but significant decomposition process at temperatures higher than $425^{\circ} \mathrm{C}$ while the former seemed to degrade with a single step. Nevertheless, the simple non isoconversional Kissinger methodology could be applied for both samples, being deduced activation energies of $166 \mathrm{~kJ} / \mathrm{mol}$ and $153 \mathrm{~kJ} / \mathrm{mol}$ for PBAdT-50 and PBSeT-50, respectively, from the linear plots given in Fig. 10a. These 
values were in close agreement with those reported for the succinic acid series (i.e. average value of $147 \mathrm{~kJ} / \mathrm{mol}$ ) demonstrating that the mechanism involved in the main degradation step should be similar for all samples, being the average value $155 \mathrm{~kJ} / \mathrm{mol}$.. The results also indicated that the obtained energies were independent of the length of the aliphatic dicarboxylic units (i.e. succinic, adipic and sebacic) and even of their content as previously discussed for the succinic acid series. Nevertheless, more accurate isoconversional analysis was necessary to corroborate the assertion.

Friedman analysis of the decomposition of PBAdT-50 revealed a practically constant activation energy (166 kJ/mol) (Fig. 11a), suggesting a single mechanism for all the degradation process that justifies the perfect agreement with Kissinger data. However, it should be pointed out that application of the KAS methodology indicated the existence of a process with lower activation energy at the lower conversions. Nevertheless, a rather constant energy close to $157 \mathrm{~kJ} / \mathrm{mol}$ could be determined for conversions higher than 0.4 .

Logically, the analysis of the PBSeT-50 main degradation peak obtained after deconvolution (Fig. 10b) gave rise to rather constant activation energies when both the Friedman and the KAS methods were applied (Fig. 11b). Calculated values of 158 and $153 \mathrm{~kJ} / \mathrm{mol}$ seemed again very close to those determined for both adipic acid and succinic acid derivatives. Note that no relationship could be found between the activation energy and the length of the dicarboxylic unit for the samples with the same molar-\% of aliphatic units. Thus, Friedman energies of $159 \mathrm{k} / / \mathrm{mol}, 166 \mathrm{~kJ} / \mathrm{mol}$ and 158 $\mathrm{kJ} / \mathrm{mol}$ were characteristic of the succinic, adipic and sebacic derivatives, oscillating the energy from an average value of $161 \mathrm{~kJ} / \mathrm{mol}$.

For the sake of completeness, the activation energy was also evaluated for the high temperature decomposition step of PBSeT-50 because the peak was well-defined after 
deconvolution. Despite the inaccuracy of this process a rather constant and clearly higher activation energy of $184 \mathrm{~kJ} / \mathrm{mol}$ (not shown) was determined.

\section{Degradation kinetic mechanism of adipate/sebacate-co-terephthalate copolyesters}

The Coats-Redfern method was again applied to determine the degradation mechanism associated with the main decomposition step of both PBAdT-50 and PBSeT-50 samples. Table 5 summarizes the activation energies determined for the different kinetic models at a representative heating rate of $10^{\circ} \mathrm{C} / \mathrm{min}$. Good correlation coefficients were found in all cases and consequently they were not useful to discriminate the best model. However, the $\mathrm{A}_{4}$ Avrami-Erofeev model gave similar activation energies as previously determined by both KAS and Friedman methods, a feature that was coincident with the analysis of the PBST series. Note for example that the activation energy of the most problematic PBSeT-50 sample was $155 \mathrm{~kJ} / \mathrm{mol}$ while KAS and Friedman energies were $153 \mathrm{~kJ} / \mathrm{mol}$ and $158 \mathrm{~kJ} / \mathrm{mol}$, respectively. The corresponding values for PBAdT-50 were $164 \mathrm{~kJ} / \mathrm{mol}$ (Coats Redfern), $157 \mathrm{~kJ} / \mathrm{mol}$ (KAS) and $166 \mathrm{~kJ} / \mathrm{mol}$ (Friedman). Table 4 summarizes also the complete kinetic triplet for both PBAdT-50 and PBSeT-50 samples together with PBST data. It is clear that minimum differences could be found between the three copolymers having the same terephthalate molar content despite having different aliphatic dicarboxylate units (i.e. succinic, adipic and sebacic acids). The approximation based on the analysis on the main peak obtained after deconvolution makes feasible to derive a single patron for thermal degradation and specifically it was inferred that the main decomposition step of aliphatic-aromatic copolyesters can be described by the same kinetic model (i.e. $\mathrm{A}_{4}$ ). This model was also corroborated by applying the Criado method [36] as shown in Fig. 12 for the representative PBSeT-50 copolymer. 


\section{CONCLUSIONS}

Copolyesters derived from 1,4-butanediol and having a random distribution of aliphatic (i.e. succinate, adipate or sebacate) and aromatic (i.e. therephthalate) units could be synthesized by a simple thermal transesterification step from the appropriate ratio of the corresponding homopolyesters and using titanium butoxide as catalyst.

Slight differences on the thermal stability were found between copolyesters differing in the length of the aliphatic dicarboxylate moiety, but the aromatic content had a negligible influence (i.e. from $30 \%$ to $70 \%$ ). The different type of terminal groups should play a significant role in the less predominant first degradation step.

Kinetic analysis demonstrated that all copolyesters degraded according to a complex mechanism since a continuous increase of activation energy with conversion was detected by applying KAS and Friedman isoconversional methodologies. Minor degradation steps were clearly remarkable for PBST-70 and PBSeT-50 samples at the lower and higher temperature ranges, respectively. Despite these differences, all studied copolyesters showed a common behaviour. Specifically, a highly predominant decomposition step that corresponded to a $\mathrm{A}_{4}$ mechanism according to both, the CoatsRedfern and Criado analyses was found. Moreover similar activation energies (143-166 $\mathrm{kJ} / \mathrm{mol})$ and frequency factors $\left(\ln \mathrm{A}\left(\mathrm{min}^{-1}\right)=25-29\right)$ were also derived demonstrating that the main degradation process of the studied copolyesters can be defined by the same kinetic triplet independently of the aliphatic/aromatic content and the type of dicarboxylate unit.

Acknowledgements. Authors are in debt to supports from MECD and FEDER (MAT2015-69547-R) and the Generalitat de Catalunya (2014SGR188). 


\section{REFERENCES}

[1] Díaz A., Katsarava R., Puiggalí J. Synthesis, properties and applications of biodegradable polymers derived from diols and dicarboxylic acids: from polyesters to poly(ester amide)s. Int. J. Mol. Sci., 15 (2014), pp. 7064-7123.

[2] C. Wang, A. Thygesen, Y. Liu, Q. Li, M. Yang, D. Dang, Z. Wang, Y. Wan, W. Lin, J. Xing. Bio-oil based biorefinery strategy for the production of succinic acid, Biotechnol. Biofuels, 6 (2013) 74.

[3] D. P. Minh, M. Besson, C. Pinel, P. Fuertes, C. Petitjean. Aqueous-phase hydrogenation of biomass-based succinic acid to 1,4-butanediol over supported bimetallic catalysts,Top. Catal., 53 (2010), pp. 1270-1273.

[4] R. Luque, J. H. Clark, K. Yoshida and P. L. Gai. Efficient aqueous hydrogenation of biomass platform molecules using supported metal nanoparticles on starbons (R), Chem. Commun., 45 (2009), pp. 5305-5307.

[5] T. Fujimaki, Processability and properties of aliphatic polyesters, 'BIONOLLE', synthesized by polycondensation reaction. Polym. Degrad. Stab., 59 (1998), pp. 209214.

[6] B. Ahn, S. Kim, Y. Kim, J. Yang, Synthesis and characterization of the biodegradable copolymers from succinic acid and adipic acid with 1, 4-butanediol. J. Appl. Polym. Sci., 82 (2001), pp. 2808-2826.

[7] M.S. Nikolic, J. Djonlagic, Synthesis and characterization of biodegradable poly (butylene succinate-co-butylene adipate)s. Polym. Degrad. Stab., 74 (2001), pp. 263270.

[8] E. Yoo, S. Im, Melting behavior of poly (butylene succinate) during heating scan by DSC. J. Polym. Sci. Part B: Polym. Phys., 37 (1999), pp. 1357-1366. 
[9] M. Niaounakis. 1 - Introduction to Biopolymers, Biopolymers Reuse, Recycling, and Disposal, William Andrew Publishing, Oxford, 2013, pp. 1-75.

[10] R. Herrera, L. Franco, A. Rodríguez-Galán, J. Puiggalí. Characterization and degradation behavior of poly(butylene adipate-co-terephthalate)s. J. Polym. Sci. A, 40 (2002), pp. 4141-4157.

[11] I. Kleeberg, C. Hetz, R.M. Kroppenstedt, R.J. Müller, W.D. Deckwer. Biodegradation of aliphatic/aromatic copolyesters by thermophilic actinomycetes. Appl. Environ. Microbiol., 64 (1998), pp. 1731-1735.

[12] U. Witt, T. Einig, M. Yamamoto, I. Kleeberg, W.D. Deckwer, R.J. Müller. Biodegradation of aliphatic-aromatic copolyesters: Evaluation of the final biodegradability and ecotoxicological impact of degradation intermediates. Chemosphere, 44 (2001), pp. 289-299.

[13] I. Kleeberg, K. Welzel, J. van den Heuvel, R.J. Müller, W.D. Deckwer. Characterization of a new extracellular hydrolase from thermobifida fusca degrading aliphatic-aromatic copolyesters. Biomacromolecules, 6 (2005), pp. 262-270.

[14] E. Marten, R.J. Müller, W.D. Deckwer. Studies on the enzymatic hydrolysis of polyesters. II. aliphatic-aromatic copolyesters. Polym. Degrad. Stab., 88 (2005), pp. $371-381$.

[15] V. Jaisankar, R. Nanthini, A. Ravi, M. Karunanidhi. A study on biodegradation of aliphatic-aromatic random copolyesters. J. Polym. Mater., 26 (2009), pp. 157-166.

[16] R.M Lum. Thermal decomposition of poly(butylene terephthalate). J. Polym. Sci., Polym. Chem. Ed., 17 (1979), pp. 203-213.

[17] F. Samperi, C. Puglisi, R. Alicata, G. Montaudo. Thermal degradation of poly(butylene terephthalate) at the processing temperature. Polym. Degrad. Stab., 83 (2004), pp. 11-17. 
[18] T. Koshiduka, T. Ohkawa, K. Takeda. Computer simulation of thermal degradation of poly(butylene terephthalate) and analytical problems of terephthalic acid in scission products. Polym. Degrad. Stab., 79 (2003), pp. 1-11.

[19] K. Chrissafis, K.M. Paraskevopoulos, D.N. Bikiaris. Thermal degradation mechanism of poly(ethylene succinate) and poly(butylene succinate): Comparative study. Thermochim. Acta, 435 (2005), pp. 142-150.

[20] H. Zhao, Y.-Z. Wang, D.Y. Wang, B. Wu, D.-Q. Chen, X.-L. Wang, K.-K. Yang. Kinetics of thermal degradation of flame retardant copolyesters containing phosphorus linked pendent groups. Polym. Degrad. Stab., 80 (2003), pp. 135- 140.

[21] T. Zorba, K. Chrissafis, K.M. Paraskevopoulos , D.N. Bikiaris. Synthesis, characterization and thermal degradation mechanism of three poly(alkylene adipate)s: Comparative study. Polym. Degrad. Stab., 92 (2007), pp. 222-230.

[22] A. Kozłowska, M. Orłowski, J. Majszczyk. Thermal and dielectric properties of biodegradable poly (butylene sebacate-co-butylene dilinoleate). Rev. Adv. Mater. Sci., 14 (2007), pp. 61-65.

[23] A. Celli, G. Barbiroli, C. Berti, F. Di Credico, C. Lorenzetti, P. Marchese, E. Marianucci. Thermal properties of poly(alkylene dicarboxylate)s derived from 1,12dodecanedioic acid and even aliphatic diols. J. Polym. Sci. Part B: Polym. Phys. Ed., 45 (2007), pp. 1053-1067.

[24] C. Berti, A. Celli, P. Marchese, G. Barbiroli, F. Di Credico, V. Verney, S. Commereuc. Novel copolyesters based on poly(alkylene dicarboxylate)s: 1 . Thermal behavior and biodegradation of aliphatic-aromatic random copolymers. Eur. Polym. J., 44 (2008), pp. 3650-3661.

[25] N. Heidarzadeh,, M. Rafizadeh, F.A. Taromi,, L.J.. del Valle, L. Franco, J. Puiggalí. Effect of hydroxyapatite nanoparticles on the degradability of random 
poly(butylene terephthalate-co-aliphatic dicarboxylate)s having a high content of terephthalic units. Polymers, 8 (2016), 253.

[26] H.E. Kissinger. Reaction kinetics in differential thermal analysis. Anal. Chem., 29 (1957), pp. 1702-1706.

[27] T. Akahira, T. Sunose. Method of determining activation deterioration constant of electrical insulating materials. Res. Report Chiba Inst. Technol., 16 (1971), pp. 22-31.

[28] H.J. Friedman. Kinetics of thermal degradation of char-forming plastics from thermogravimetry. Polym. Sci. C, 6 (1964), pp. 183-195.

[29] H.L. Friedman. A quick, direct method for the determination of activation energy from thermogravimetric data. J. Polym. Lett., 4 (1966), pp. 323-328.

[30] H.E. Kissinger. Reaction kinetics in differential thermal analysis. Anal. Chem., 29 (1957), pp. 1702-1706.

[31] N. Sbirrazzuoli, Y. Girault, L. Elegant. Simulations for evaluation of kinetic methods in differential scanning calorimetry. 3. Peak maximum evolution methods and isoconversional methods. Thermochim. Acta, 293 (1997), pp.25-37.

[32] S. Vyazovkin, N. Sbirrazzuoli. Isoconversional kinetic analysis of thermally stimulated processes in polymers. Macromol. Rapid Commun., 27 (2006), pp. 15151532.

[33] A.W. Coats, J.P. Redfern. Kinetic parameters from thermogravimetric data. Nature 201 (1964), 68.

[34] A.B. Phadnis. Determination of the kinetics and mechanism of a solid-state reaction—a simple approach. Thermochim. Acta, 62 (1983), pp. 361-367.

[35] S. Vyazovkin, D.J. Dollimore. Linear and nonlinear procedures in isoconversional computations of the activation energy of nonisothermal reactions in solids. Chem. Inform. Comput. Sci., 36 (1996), pp. 42-45. 
[36] P.E. Sánchez-Jiménez, L.A. Pérez-Maqueda, A. Perejón, J.M. Criado. A new model for the kinetic analysis of thermal degradation of polymers driven by random scission. Polym. Degrad. Stab. 95 (2010), pp. 733-739.

[37] J. Fernández, A. Etxeberria, J.M Ugartemendia, S. Petisco, J.R, Sarasua. Effects of chain microstructures on mechanical behavior and aging of poly(L-lactide-co- $\varepsilon$ caprolactone) biomedical thermoplastic-elastomer, J. Mech. Behav. Biomed. Mater. 12 (2012), pp. 29-38.

[38] J. Fernández, A. Etxeberria, J.R. Sarasua. Synthesis, structure and properties of poly(L-lactide-co- $\varepsilon$-caprolactone) statistical copolymers. J. Mech. Behav. Biomed. Mater. 9 (2012), pp. 100-112.

[39] C.D. Doyle. Kinetic analysis of thermogravimetric data. J. Appl. Polym. Sci., 5 (1961), pp. 285-292.

[40] P.M. Madhysudanan, K. Krishnan, K.N. Ninan. New equations for kinetic analysis of non-isothermal reactions. Thermochimica Acta, 221 (1993), pp. 13-21.

[41] W. Tang W, Y. Liu, H. Zang, C. Wang. New approximate formula for Arrhenius temperature integral. Thermochimica Acta 408 (2003), pp. 39-43 (2003).

[42] T. Wanjun, L. Yuwen, Z. Hen, W. Zhiyong, W. Cunxin. New temperature integral approximate formula for non-isothermal kinetic analysis. J. Therm. Anal. Calorim. 74 (2003), pp. 309-315. 


\section{FIGURE CAPTIONS}

Fig. 1. Scheme showing the random distribution of aliphatic and aromatic dicarboxylic units attained after the thermal transesterification reaction of the corresponding homopolymers.

Fig. 2. ${ }^{1} \mathrm{H}$ NMR spectrum of PBAdT-50. The inset shows a magnification of the 4.704.25 ppm region for PBST-50 (left), PBAdT-50 (middle) and PBSeT-50 (right) where $\mathrm{OCH}_{2}$ sequence sensitive signals appear.

Fig. 3. Degree of conversion $(\alpha)$ versus temperature and derivative curves for the decomposition of PBST-30 (a), PBST-50 (b) and PBST-70 (c) copolymers. Curves are drawn from left to right in increasing order of heating rates $\left(3,5,10\right.$ and $\left.20{ }^{\circ} \mathrm{C} / \mathrm{min}\right)$. Red and blue arrows point out the shoulder/peak observed at low and intermediate temperatures, respectively. Dashed ellipsoids emphasize the asymmetry of DTG curves in the low temperature range.

Fig. 4. Degree of conversion $(\alpha)$ versus temperature and derivative curves for the decomposition of PBAdT-50 (a) and PBSeT-50 (b) copolymers (from left to right on increasing heating rates). Red arrows point out the /peak observed at high temperature.

Figure 5. Activation energy versus conversion calculated by the KAS (•) and Friedman (०) methods for degradation of the representative PBST-70 copolymer.

Fig. 6. a) Deconvolution for DTG curve $\left(3{ }^{\circ} \mathrm{C} / \mathrm{min}\right)$ of PBST-70 copolymer. b) Plots of the activation energy calculated by the KAS $(\bullet)$ and Friedman (०) methods for degradation of the PBST-70 copolymer after performing deconvolution. Dashed lines indicate the average activation energy over the conversion range where it can be considered practically constant. 
Fig. 7. Activation energy versus conversion calculated by the KAS (•) and Friedman (o) methods for the main degradation step of PBST-30 (a) and PBST-50 (b) copolymers. Dashed lines indicate the average activation energy over the conversion range where it can be considered practically constant.

Fig. 8. Kissinger plots of the main degradation step of PBST-30 (•), PBST-50 (०) PBST-70 ( $\mathbf{\nabla})$.

Fig. 9. Comparison of the $f(\alpha)$ functions (solid lines) normalized at $\alpha=0.5$ corresponding to ideal kinetic models (i.e. right hand side of Eq. (6) applied to selected conversions) and data corresponding to a heating rate of $20^{\circ} \mathrm{C} / \mathrm{min}$ for PBST-70. Red line emphasizes the $\mathrm{A}_{4}$ kinetic model. Dashed line corresponds to the experimental data plot.

Fig. 10. a) Kissinger plots of the main degradation step of PBAdT-50 (•) and PBSeT-50 (०). b) Deconvolution for DTG curve $\left(3{ }^{\circ} \mathrm{C} / \mathrm{min}\right)$ of PBSeT-50 copolymer.

Fig. 11. Plots of the activation energy calculated by the KAS (•) and Friedman (०) methods for the main degradation step of PBAdT-50 (a) and PBSeT-50 (b) copolymers. Dashed lines indicate the average activation energy over the conversion range where it can be considered practically constant.

Fig. 12. Comparison of the $f(\alpha)$ functions (solid lines) normalized at $\alpha=0.5$ corresponding to ideal kinetic models (i.e. right hand side of Eq. (6) applied to selected conversions) and data corresponding to a heating rate of $20^{\circ} \mathrm{C} / \mathrm{min}$ for PBSeT-50. Red line emphasizes the $\mathrm{A}_{4}$ kinetic model. Dashed line corresponds to the experimental data plot. 
Table 1. Composition, molecular weight, polydispersity index, block lengths and degree of randomness of synthesized copolymers.

\begin{tabular}{ccccccc}
\hline \multirow{2}{*}{ Copolymer } & \multirow{2}{*}{$\boldsymbol{f}_{\boldsymbol{A}}$} & $\begin{array}{c}\boldsymbol{M}_{\mathbf{w}} \\
(\mathbf{g} / \mathbf{m o l})\end{array}$ & \multirow{2}{*}{ PDI } & \multicolumn{2}{c}{ Block lengths } & \multirow{2}{*}{$\boldsymbol{r}$} \\
\cline { 5 - 6 } & & & $\boldsymbol{L}_{\boldsymbol{n} \boldsymbol{n} \boldsymbol{B} \boldsymbol{B}}$ & $\boldsymbol{L}_{\boldsymbol{n} \boldsymbol{A B}}$ & \\
PBST-30 & 0.35 & 20206 & 2.12 & 2.63 & 1.53 & 1.03 \\
PBST-50 & 0.56 & 18868 & 2.24 & 1.64 & 2.72 & 1.05 \\
PBAdT-50 & 0.53 & 13904 & 2.62 & 1.89 & 2.13 & 1.00 \\
PBSeT-50 & 0.57 & 17446 & 2.59 & 1.75 & 2.24 & 1.02 \\
PBST-70 & 0.74 & 12515 & 2.36 & 1.37 & 3.33 & 1.03 \\
\hline
\end{tabular}


Table 2. Thermal degradation data of synthesized copolymers at different heating rates.

\begin{tabular}{cccccc}
\hline Sample & $\begin{array}{c}\boldsymbol{\beta} \\
\left(^{\mathbf{}} \mathbf{C} / \mathbf{m i n}\right)\end{array}$ & $\begin{array}{c}\mathbf{T}_{\mathbf{o n s e t}^{\mathbf{a}}} \\
\left.\mathbf{(}^{\mathbf{}} \mathbf{C}\right)\end{array}$ & $\mathbf{T}_{\mathbf{0 . 2}}$ & $\mathbf{T}_{\mathbf{0 . 5}}$ & $\mathbf{T}_{\mathbf{0 . 7}}$ \\
\hline PBST-30 & 3 & 262 & 353 & 371 & 379 \\
& 5 & 280 & 358 & 377 & 386 \\
& 10 & 289 & 378 & 396 & 404 \\
PBST-50 & 20 & 309 & 396 & 413 & 422 \\
& 3 & 252 & 350 & 369 & 379 \\
& 5 & 253 & 358 & 378 & 388 \\
PBAdT-50 & 10 & 289 & 377 & 395 & 404 \\
& 20 & 303 & 393 & 412 & 421 \\
& 3 & 294 & 359 & 375 & 382 \\
PBSeT-50 & 5 & 298 & 369 & 384 & 392 \\
& 10 & 308 & 384 & 400 & 408 \\
& 20 & 312 & 400 & 416 & 424 \\
& 3 & 302 & 367 & 380 & 388 \\
& 5 & 306 & 375 & 388 & 396 \\
PBST-70 & 10 & 321 & 390 & 403 & 412 \\
& 20 & 337 & 409 & 423 & 431 \\
& 3 & 294 & 344 & 366 & 376 \\
& 5 & 325 & 357 & 378 & 388 \\
& 10 & 347 & 377 & 397 & 407 \\
& 20 & 360 & 387 & 408 & 418 \\
\hline
\end{tabular}

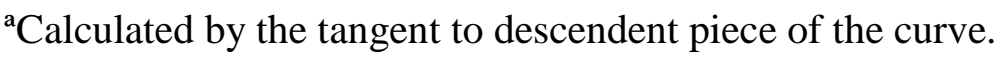


Table 3. Activation energies and correlation coefficients for the main degradation step of PBST-

70 considering the different kinetic obtained and applying the Coats-Redfern method.

\begin{tabular}{|c|c|c|c|c|c|c|c|c|}
\hline \multirow{2}{*}{ Model } & \multicolumn{2}{|c|}{$3^{\circ} \mathrm{C} / \mathrm{min}$} & \multicolumn{2}{|c|}{$5^{\circ} \mathrm{C} / \mathrm{min}$} & \multicolumn{2}{|c|}{$10^{\circ} \mathrm{C} / \mathrm{min}$} & \multicolumn{2}{|c|}{$20^{\circ} \mathrm{C} / \mathrm{min}$} \\
\hline & $\begin{array}{c}E \\
(\mathrm{~kJ} / \mathrm{mol})\end{array}$ & $r$ & $\begin{array}{c}E \\
(\mathrm{~kJ} / \mathrm{mol})\end{array}$ & $r$ & $\begin{array}{c}E \\
(\mathrm{~kJ} / \mathrm{mol})\end{array}$ & $r$ & $\begin{array}{c}E \\
(\mathrm{~kJ} / \mathrm{mol})\end{array}$ & $r$ \\
\hline Power & 264 & 0.9986 & 336 & 0.9993 & 228 & 0.9976 & 340 & 0.9991 \\
\hline $\mathrm{F} 1$ & 541 & 0.9988 & 541 & 0.9993 & 478 & 0.9983 & 692 & 0.9992 \\
\hline $\mathrm{A} 3 / 2$ & 357 & 0.9988 & 452 & 0.9993 & 315 & 0.9982 & 457 & 0.9992 \\
\hline $\mathrm{A} 2$ & 265 & 0.9987 & 337 & 0.9993 & 234 & 0.9982 & 340 & 0.9992 \\
\hline A3 & 173 & 0.9987 & 221 & 0.9992 & 152 & 0.9981 & 223 & 0.9990 \\
\hline A4 & 150 & 0.9986 & 163 & 0.9993 & 141 & 0.9980 & 163 & 0.9989 \\
\hline $\mathrm{R} 2$ & 550 & 0.9987 & 683 & 0.9993 & 473 & 0.9980 & 691 & 0.9992 \\
\hline R3 & 540 & 0.9988 & 683 & 0.9993 & 474 & 0.9981 & 691 & 0.9993 \\
\hline D1 & 1088 & 0.9987 & 1376 & 0.9993 & 945 & 0.9978 & 1392 & 0.9986 \\
\hline D2 & 1100 & 0.9988 & 1387 & 0.9993 & 963 & 0.9980 & 1403 & 0.9993 \\
\hline D3 & 540 & 0.9988 & 1376 & 0.9993 & 960 & 0.9981 & 1393 & 0.9993 \\
\hline D4 & 1090 & 0.9988 & 1376 & 0.9993 & 955 & 0.9980 & 1393 & 0.9993 \\
\hline $\mathrm{n}=1.5$ & 542 & 0.9988 & 683 & 0.9993 & 484 & 0.9985 & 692 & 0.9993 \\
\hline$n=2$ & 543 & 0.9989 & 683 & 0.9993 & 489 & 0.9987 & 683 & 0.9992 \\
\hline $\mathrm{n}=3$ & 545 & 0.9990 & 683 & 0.9993 & 500 & 0.9991 & 693 & 0.9993 \\
\hline $\mathrm{n}=1.5 ; \mathrm{m}=0.5$ & 266 & 0.9988 & 337 & 0.9993 & 239 & 0.9987 & 341 & 0.9992 \\
\hline $\mathrm{n}=1.9 ; \mathrm{m}=0.1$ & 488 & 0.9989 & 614 & 0.9993 & 439 & 0.9987 & 622 & 0.9993 \\
\hline
\end{tabular}


Table 4. Kinetic parameters determined for the studied copolymers.

\begin{tabular}{cccccc}
\hline Copolymer & \multicolumn{3}{c}{ E $(\mathbf{k J} / \mathbf{m o l})$} & Model & $\begin{array}{c}\text { Frequency factor } \\
\text { ln }\left(\mathbf{A} / \mathbf{m i n}^{-\mathbf{1}}\right)^{\mathbf{a}}\end{array}$ \\
\cline { 2 - 3 } & KAS & Friedman & Coats-Redfern $^{\mathbf{a}}$ & & \\
\hline PBST-30 & 143 & 156 & 161 & $\mathrm{~A}_{4}$ & 28 \\
PBST-50 & 147 & 159 & 163 & $\mathrm{~A}_{4}$ & 28 \\
PBAdT-50 & 157 & 166 & 166 & $\mathrm{~A}_{4}$ & 29 \\
PBSeT-50 & 153 & 158 & 155 & $\mathrm{~A}_{4}$ & 25 \\
PBST-70 & 143 & 171 & 127 & $\mathrm{~A}_{4}$ & 27 \\
PBST-70 & 151 & 161 & 154 & $\mathrm{~A}_{4}$ & 26 \\
\hline
\end{tabular}

${ }^{\text {a }}$ Values determined by considering all heating rates (i.e. 3, 5, 10 and $20{ }^{\circ} \mathrm{C} / \mathrm{min}$ ).

${ }^{\mathrm{b}}$ Data from the deconvoluted DTGA profiles. 
Table 5. Activation energies and correlation coefficients obtained by the Coats-Redfern method for the main degradation step of PBAdT-50 (10 $\left.{ }^{\circ} \mathrm{C} / \mathrm{min}\right)$ and PBSeT-50 $\left(10^{\circ} \mathrm{C} / \mathrm{min}\right)$ copolymers.

\begin{tabular}{ccccc}
\hline \multirow{2}{*}{ Model } & \multicolumn{2}{c}{ PBAdT-50 } & \multicolumn{2}{c}{ PBSeT-50 } \\
\cline { 2 - 5 } & $\boldsymbol{E} \mathbf{( k J / m o l )}$ & $\boldsymbol{r}$ & $\boldsymbol{E} \mathbf{( k J / m o l )}$ & $\boldsymbol{r}$ \\
\hline power & 374 & 0.9996 & 326 & 0.9977 \\
F1 & 773 & 0.9997 & 649 & 0.9982 \\
$\mathrm{~A} 3 / 2$ & 510 & 0.9995 & 377 & 0.9976 \\
$\mathrm{~A} 2$ & 380 & 0.9996 & 339 & 0.9982 \\
$\mathrm{~A} 3$ & 249 & 0.9998 & 235 & 0.9989 \\
$\mathrm{~A} 4$ & 166 & 0.9998 & 155 & 0.9989 \\
$\mathrm{R} 2$ & 763 & 0.9992 & 693 & 0.9987 \\
$\mathrm{R} 3$ & 766 & 0.9994 & 656 & 0.9975 \\
$\mathrm{D} 1$ & 1523 & 0.9995 & 1315 & 0.9983 \\
$\mathrm{D} 2$ & 1543 & 0.9993 & 1365 & 0.9982 \\
$\mathrm{D} 3$ & 1542 & 0.9996 & 1302 & 0.9987 \\
$\mathrm{D} 4$ & 1536 & 0.9995 & 1257 & 0.9983 \\
$n=1.5$ & 777 & 0.9998 & 671 & 0.9975 \\
$n=2$ & 785 & 0.9996 & 669 & 0.9981 \\
$n=3$ & 799 & 0.9995 & 653 & 0.9982 \\
$n=1.5, m=0.5$ & 387 & 0.9994 & 323 & 0.9979 \\
$n=1.9, m=0.1$ & 705 & 0.9996 & 578 & 0.9980 \\
\hline
\end{tabular}




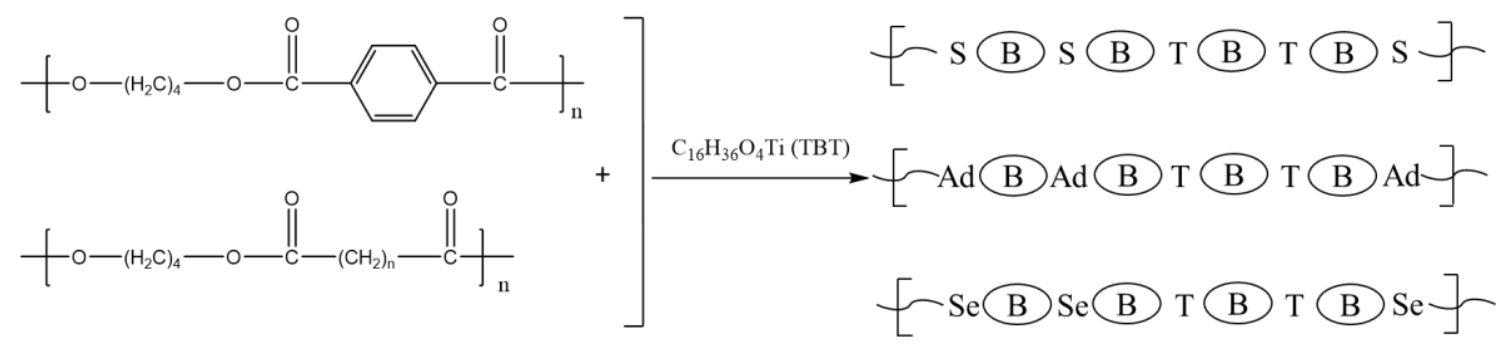

Figure 1

Heidarzadeh et al. 


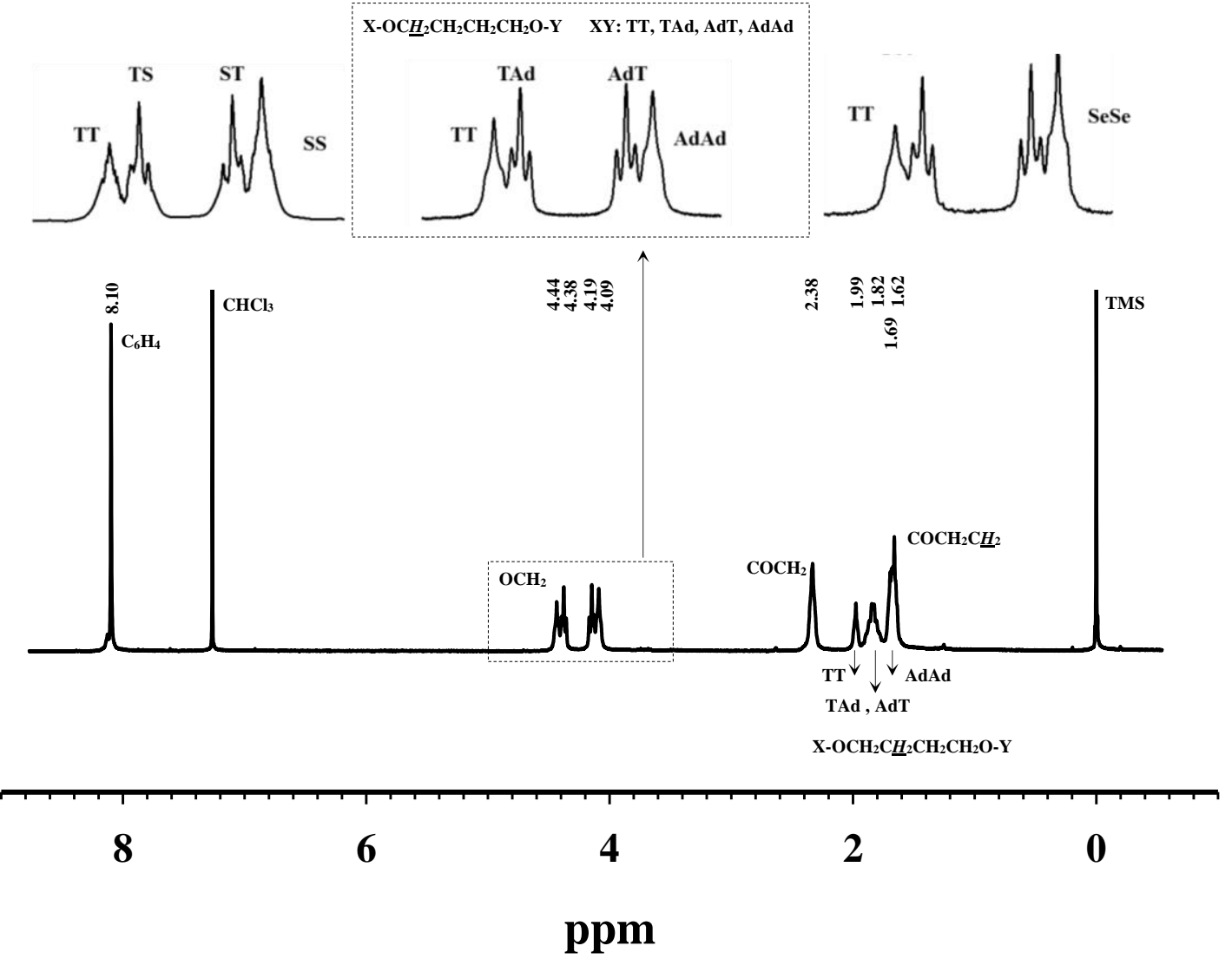

Figure 2

Heidarzadeh $e t$ al. 

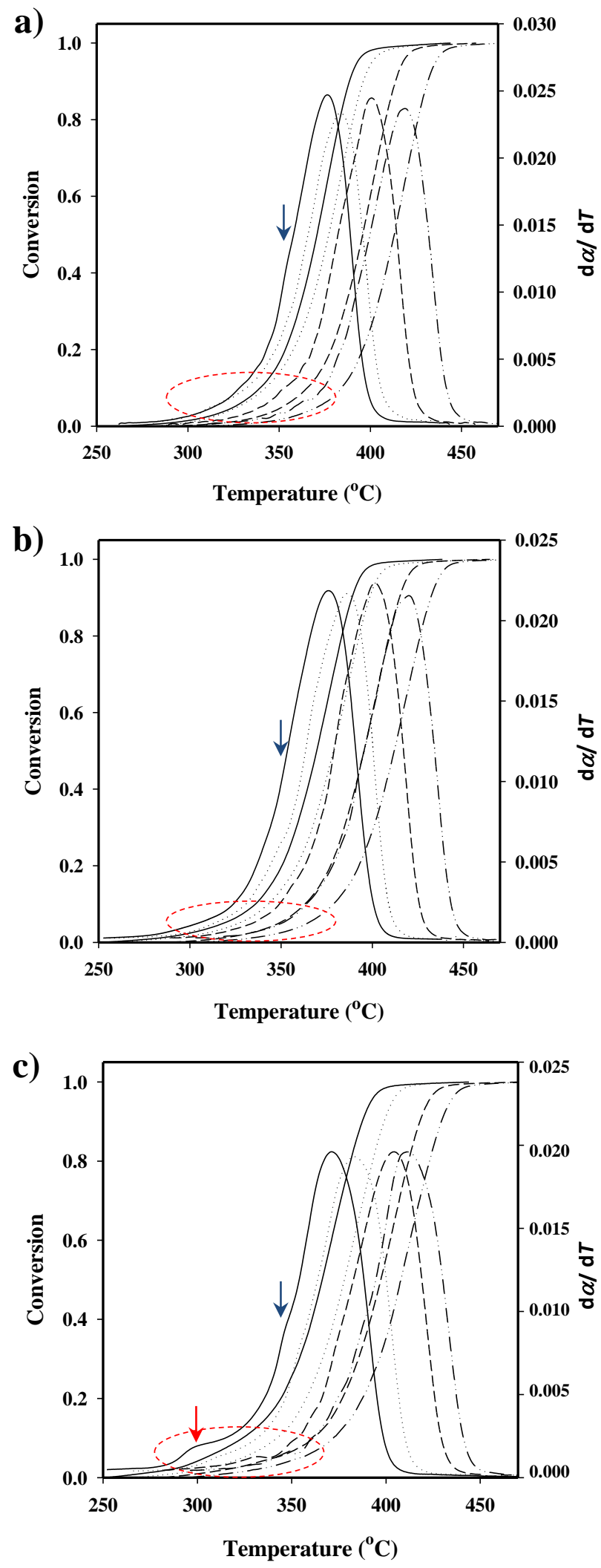

Figure 3

Heidarzadeh et al. 

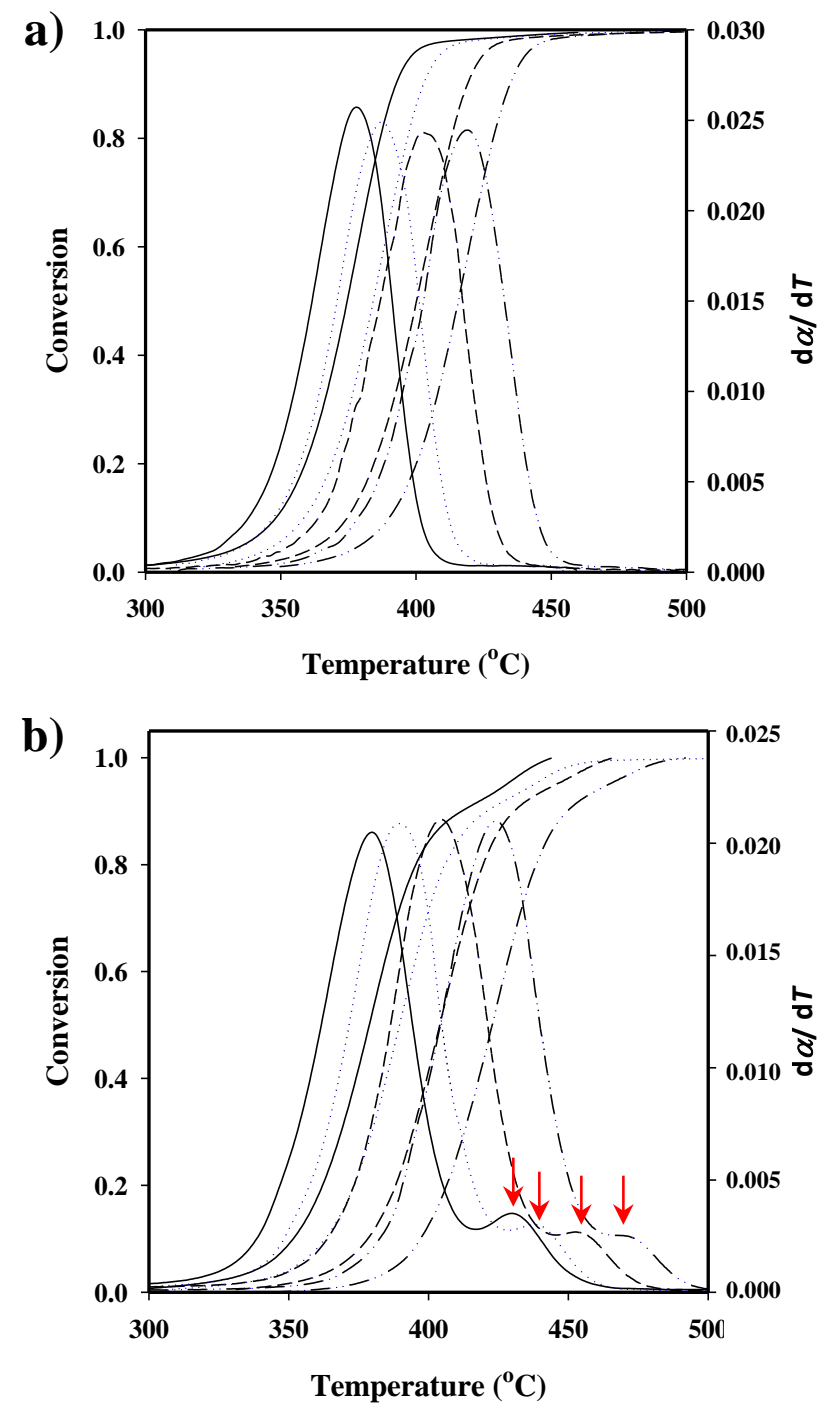

Figure 4

Heidarzadeh et al. 


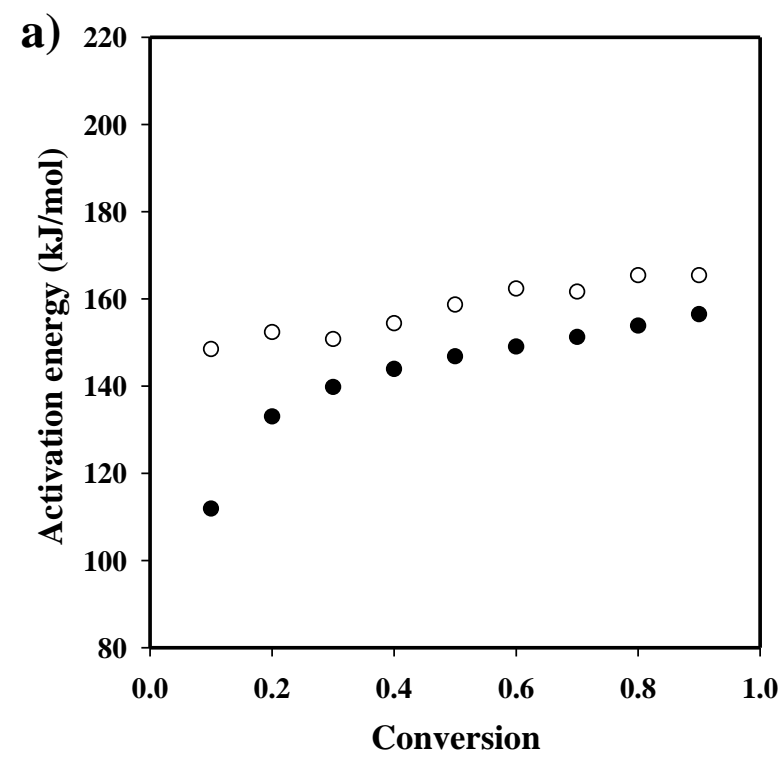

Figure 5

Heidarzadeh $e t$ al. 

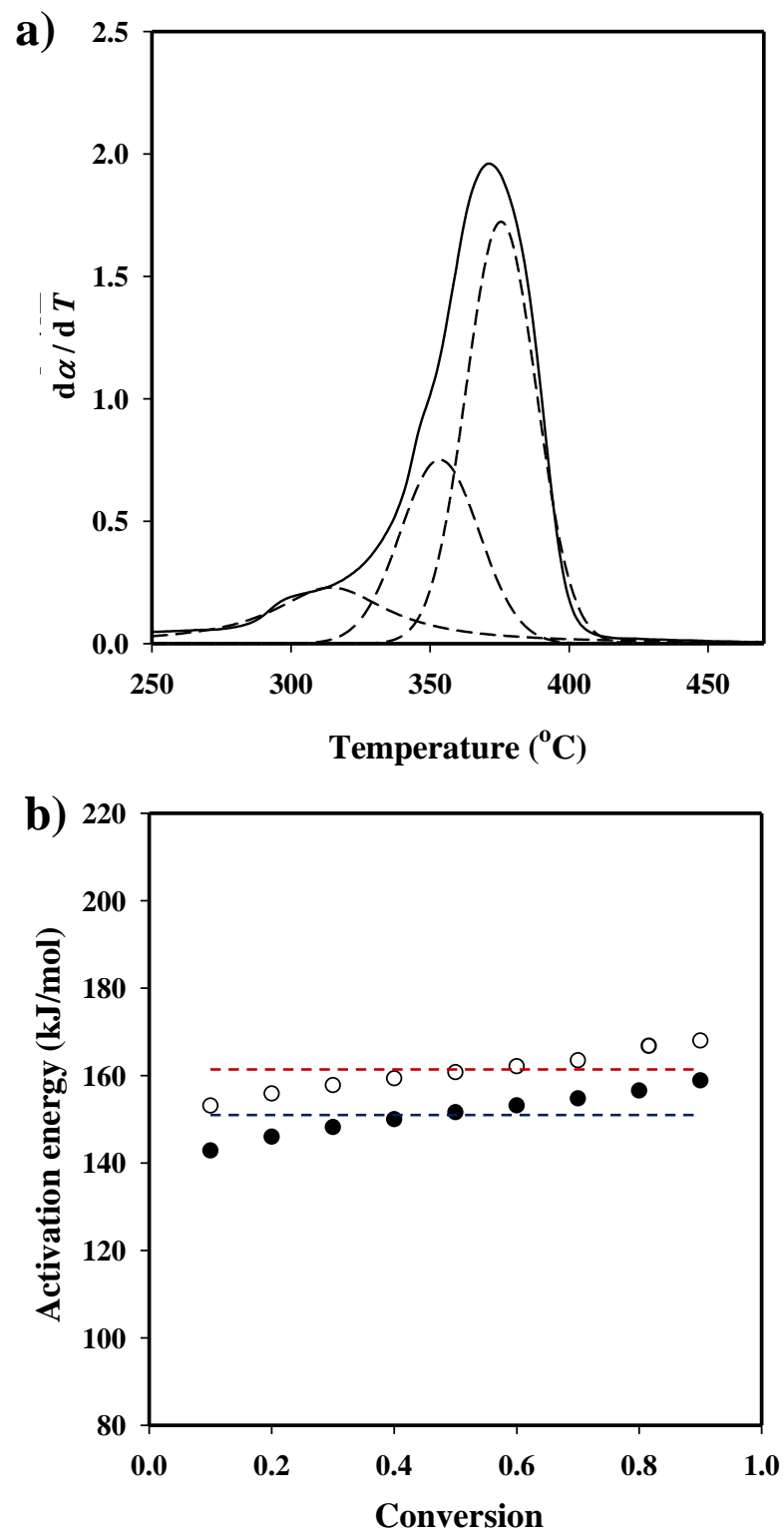

Figure 6

Heidarzadeh et al. 

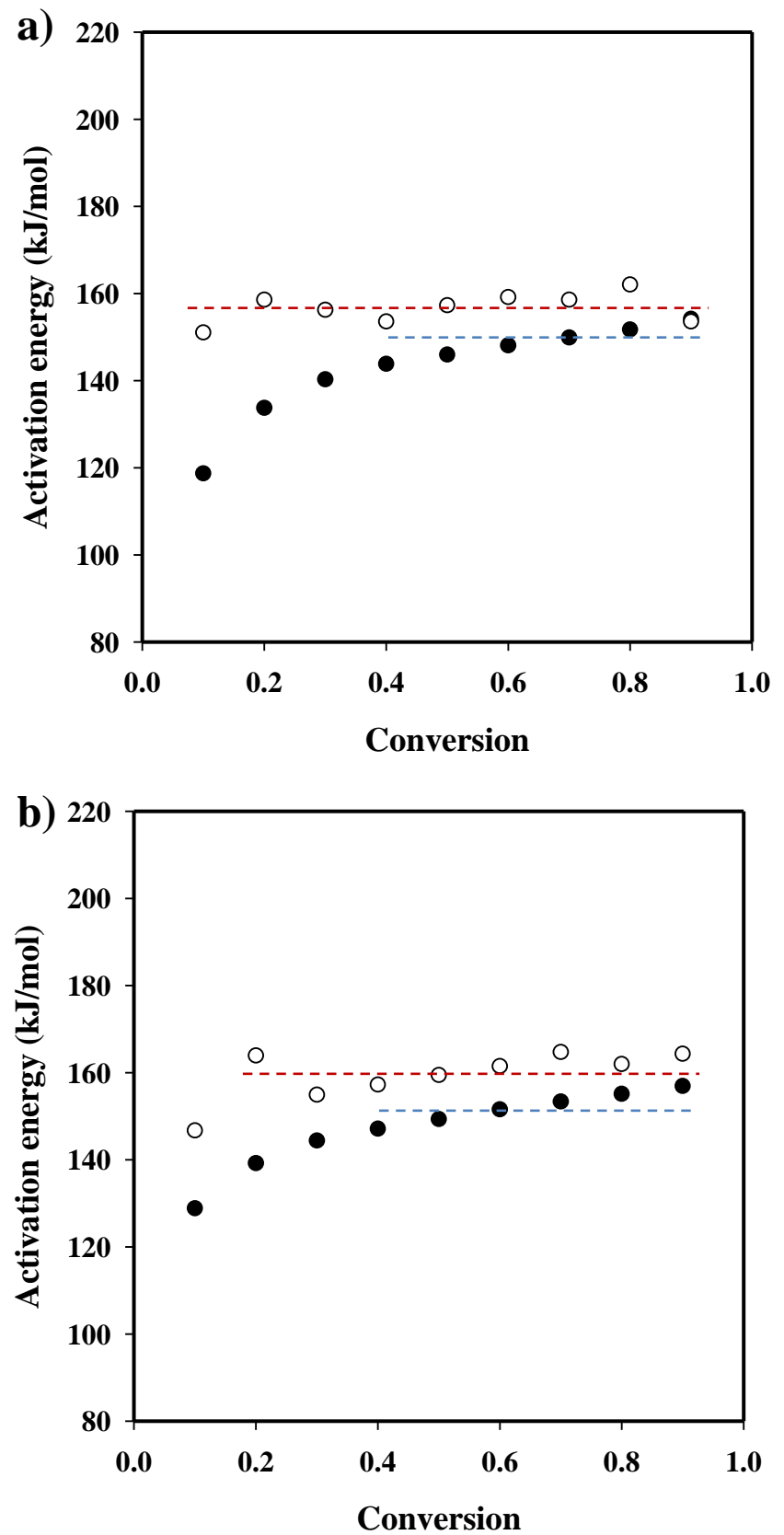

Figure 7

Heidarzadeh et al. 


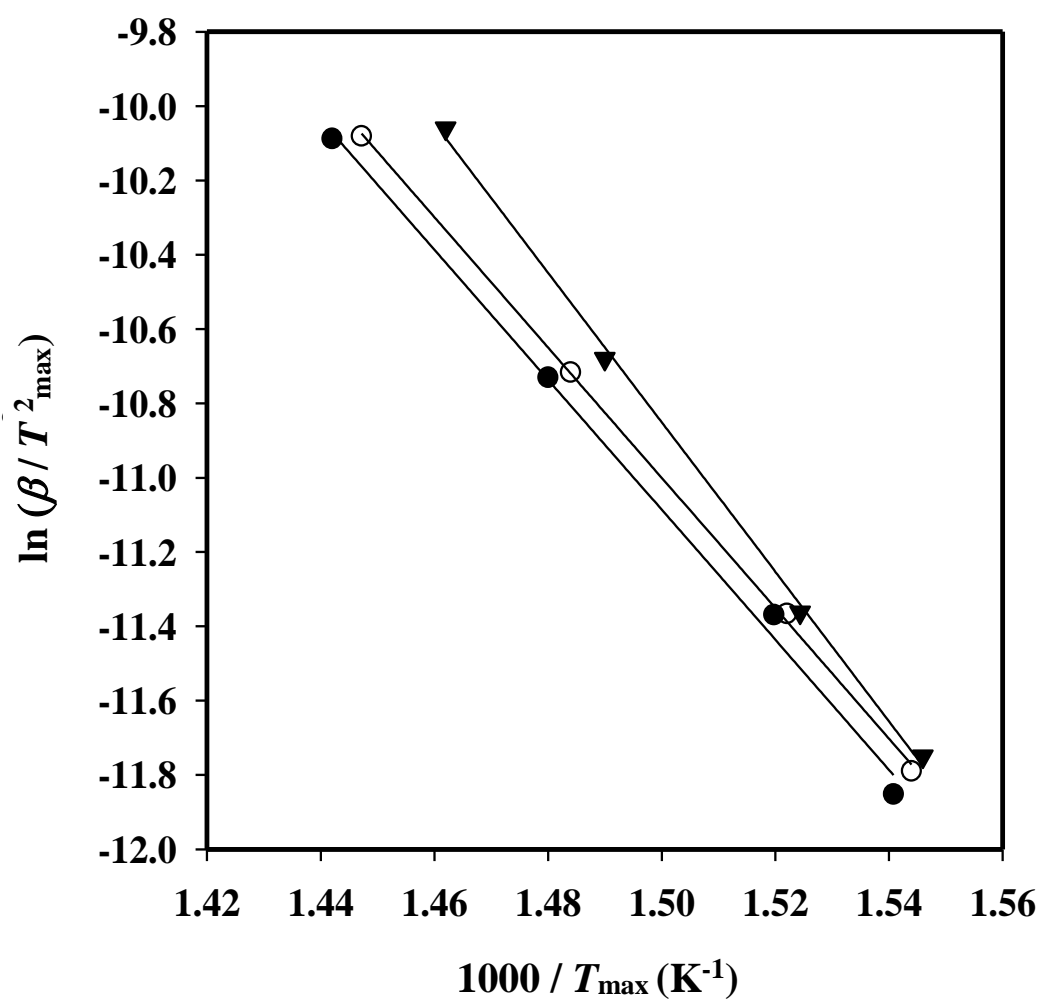

Figure 8

Heidarzadeh et al. 


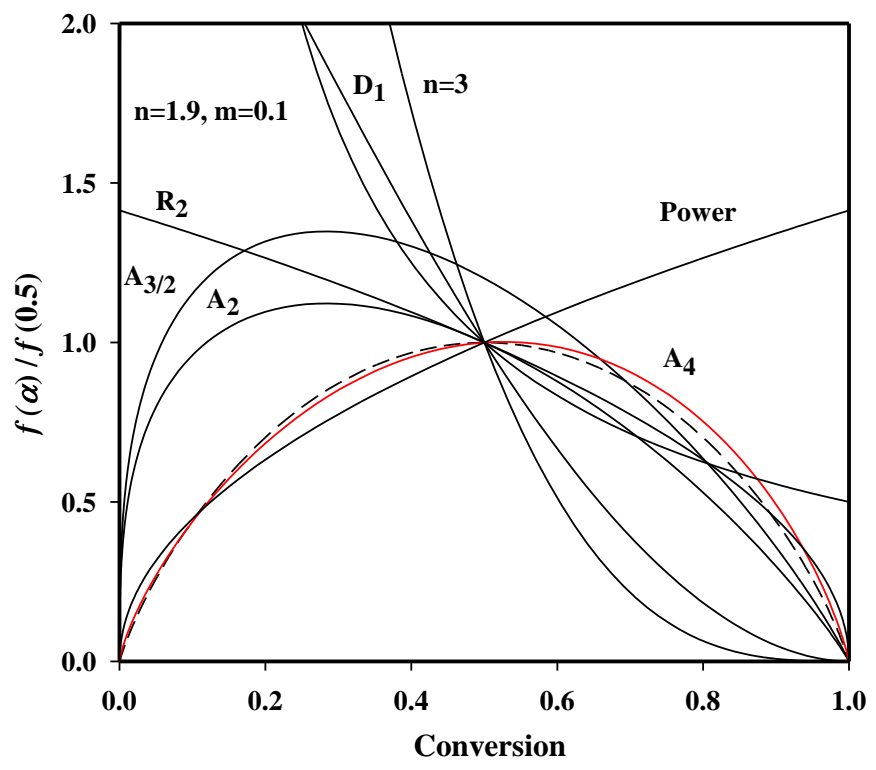

Figure 9

Heidarzadeh et al. 

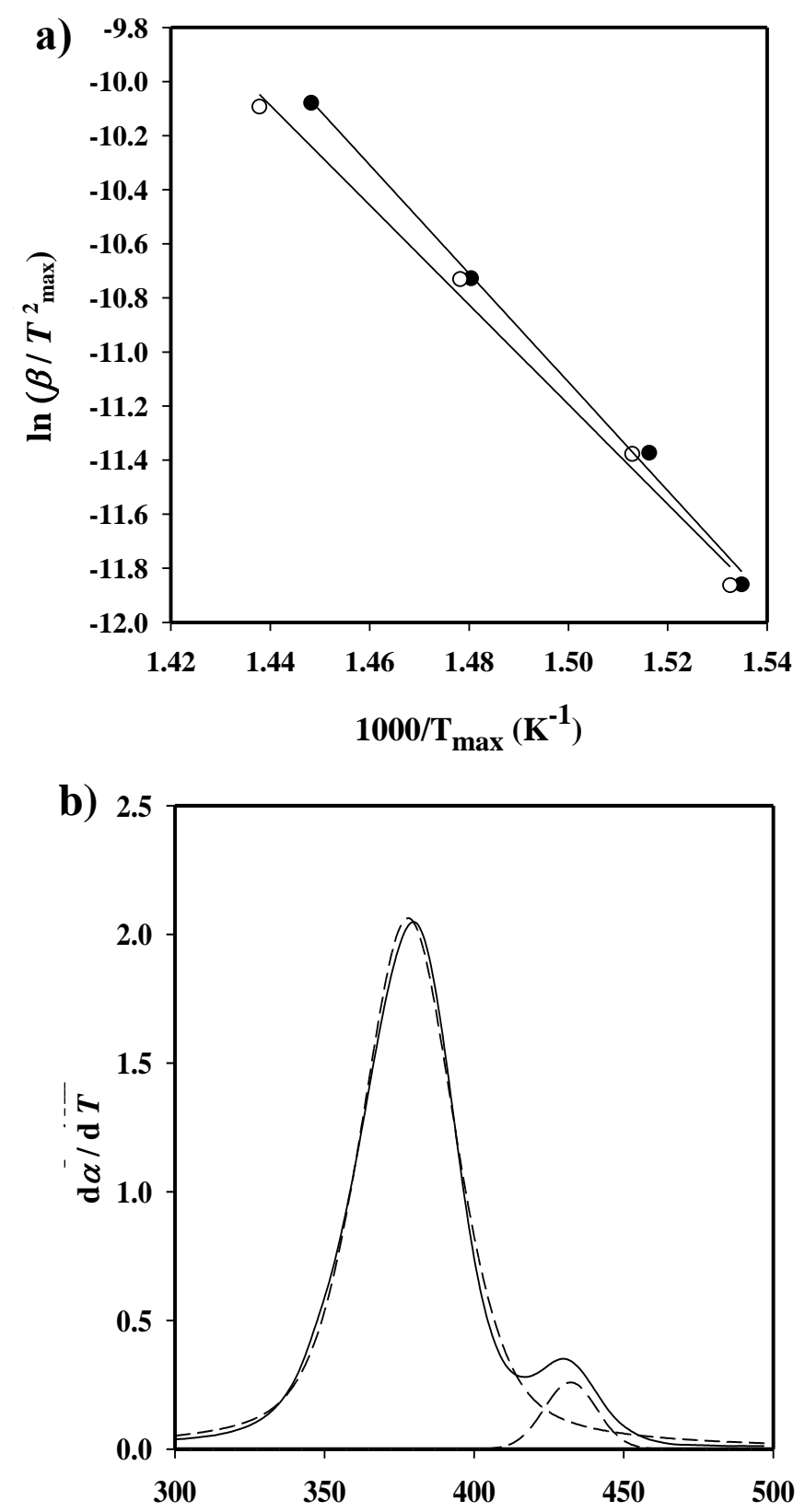

Temperature $\left({ }^{\circ} \mathrm{C}\right)$ 

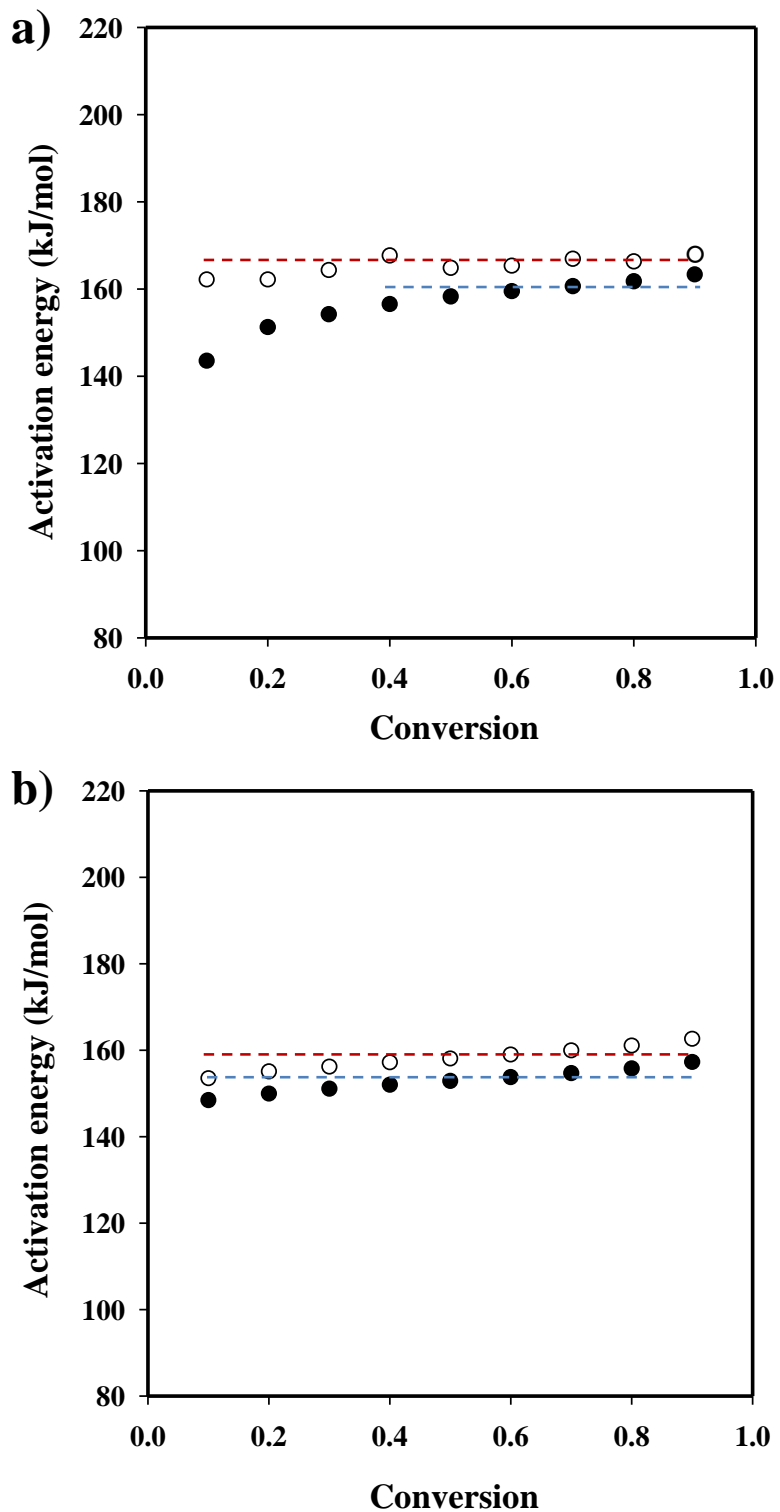

Figure 11

Heidarzadeh et al. 


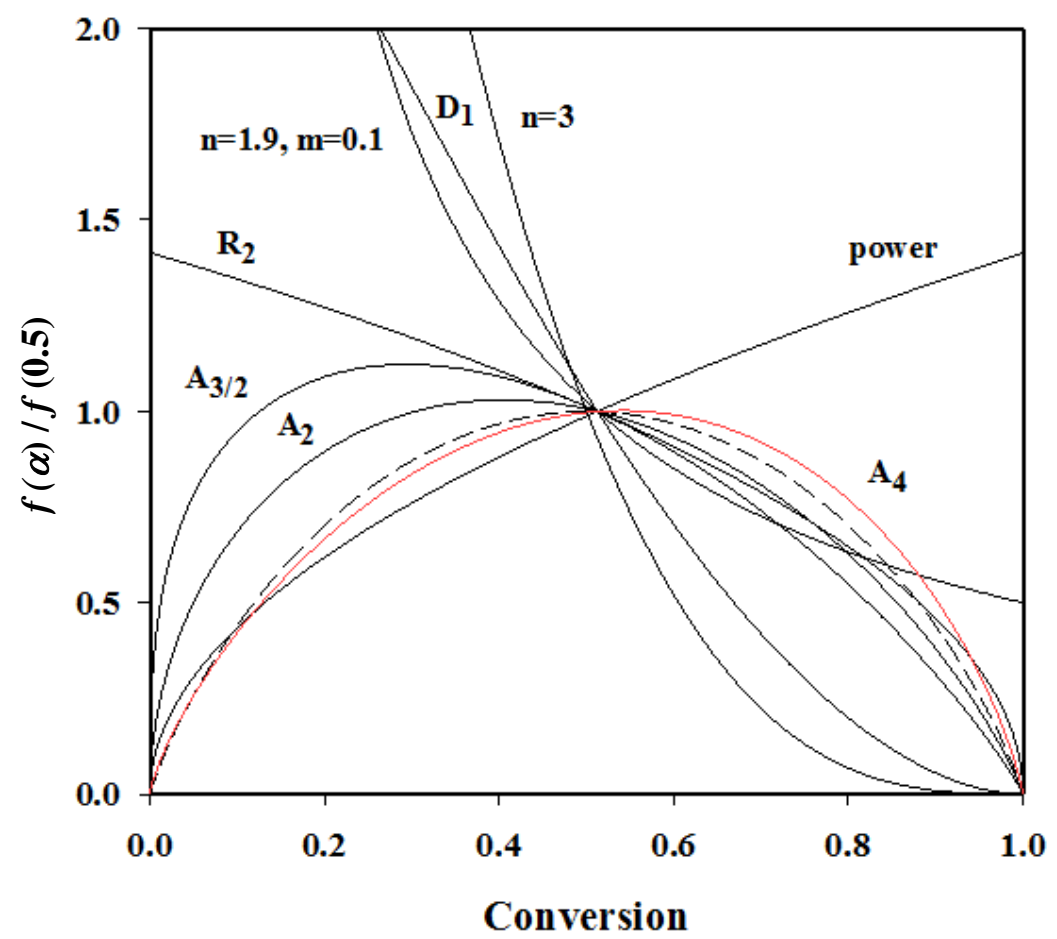

Figure 12

Heidarzadeh et al. 